(2) Open Access Full Text Article

\title{
Preparation and characterization of solid lipid nanoparticles containing cyclosporine by the emulsification-diffusion method
}

This article was published in the following Dove Press journal:

International Journal of Nanomedicine

18 August 2010

Number of times this article has been viewed

\author{
Zaida Urbán-Morlán' \\ Adriana Ganem-Rondero' \\ Luz María Melgoza- \\ Contreras $^{2}$ \\ José Juan Escobar-Chávez'1,2 \\ María Guadalupe Nava- \\ Arzaluz' \\ David Quintanar-Guerrero' \\ 'División de Estudios de Posgrado \\ (Tecnología Farmacéutica), Facultad \\ de Estudios Superiores Cuautitlán- \\ Universidad Nacional Autónoma \\ de México, Estado de México, \\ México; ${ }^{2}$ Departamento de Sistemas \\ Biológicos, Universidad Autónoma \\ Metropolitana-Xochimilco, Calzada del \\ Hueso, Colonia Villa Quietud, México
}

Correspondence: David QuintanarGuerrero

Bolognia 4-28, Bosques del Lago, Cuautitlán Izcalli, Estado de México, CP 54766, México

Tel +52 $555877 \quad 1907$

Fax +52 5558938675

Email quintana@servidor.unam.mx

\begin{abstract}
Solid lipid nanoparticles (SLNs) have been used for carrying different therapeutic agents because they improve absorption and bioavailability. The aim of the study was to prepare lipidic nanoparticles containing cyclosporine (CyA) by the emulsification-diffusion method and to study their physicochemical stability. Glyceryl behenate (Compritol ${ }^{\circledR}$ ATO 888) and lauroyl macrogolglycerides (Gelucire ${ }^{\circledR} 44 / 14$ ) were used as carrier materials. Nanoparticles with good stability were obtained with Gelucire ${ }^{\circledR}$, while it was difficult to obtain stable systems with Compritol $^{\circledR}$. Systems with Gelucire ${ }^{\circledR}$ were characterized by particle size, Z-potential, differential scanning calorimetry (DSC), scanning electron microscopy (SEM), entrapment efficiency and in vitro release. Particle size and Z-potential were evaluated for at least three months. With a high CyA content ( $\geq 60 \mathrm{mg}$ ) in Gelucire ${ }^{\circledR}$ SLNs, variations in size were greater and particle size also increased over time in all batches; this effect may have been caused by a probable expulsion of the drug due to the lipid's partial rearrangement. While the Z-potential decreased $10 \mathrm{mV}$ after three months, this effect may be explained by the superficial properties of the drug that make the molecules to be preferably oriented at the solid-liquid interface, causing a change in the net charge of the particle. SEM confirmed size and shape of the nanoparticles. DSC studies evidenced that CyA affects the lipid structure by a mechanism still unknown. The entrapment efficiency was higher than $92 \%$, and CyA release from SLNs was relatively fast (99.60\% in $45 \mathrm{~min}$ ).
\end{abstract}

Keywords: emulsification-diffusion method, solid lipid nanoparticles, glyceryl behenate, lauroyl macrogolglycerides, dispersion stability, cyclosporine

\section{Introduction}

In the 90s, a new type of carrier was developed, the so-called solid lipid nanoparticles (SLNs) which have been studied and modified from the original concept into more complex systems (eg, nanostructured lipid carriers or lipid-drug conjugate), ${ }^{1,2}$ but basically the usage of lipid materials to form the carrier has presented many advantages over other kinds of materials. Advances in this field of investigation are reported in literature mainly related to the method of production (eg, electrospray technique, ${ }^{3}$ coacervation) ${ }^{4}$ the type of drug being encapsulated (eg, water soluble drugs, ${ }^{5}$ gene delivery), ${ }^{6}$ or the enhancement of bioavailability and absorption (eg, pentoxifylline, ${ }^{7}$ digoxin). ${ }^{8}$

SLNs are submicron-sized carriers composed of a lipid solid matrix stabilized by a surfactant. Such systems have some advantages over other colloidal carriers (nanoemulsions, microparticles, polymeric nanoparticles, liposomes, etc), such as low toxicity, high drug payload, capability of including lipophilic and hydrophilic drugs, drug targeting, controlled release (fast or sustained), and occlusive properties. ${ }^{9}$ 
SLNs can be produced by many methods, although the following are the most common: i) hot high pressure homogenization (HPH) technique and cold HPH technique; ii) solvent emulsification/evaporation (SEE); iii) high shear homogenization (HSH) and/or ultrasound, and iv) microemulsion. ${ }^{10}$

The most popular method is HPH; however, with both techniques (hot and cold), the drug, lipid, or other components may suffer chemical degradation due to the need of melting the lipid and/or to the increment of sample temperature during the process. Class I (highly toxic) or Class II (toxic) International Conference on Harmonization solvents are required to obtain SLNs by the SEE method, thus, its use is limited because of toxicological implications. With HSH and/or ultrasound, there is a broad particle size distribution and the product can be contaminated during the ultrasonication step. These factors may lead to particle growth and physical instability. The microemulsion method has the disadvantage of requiring high concentrations of surfactants and co-surfactants, and a great quantity of water should be eliminated from the final product.

Recently, Quintanar-Guerrero et $\mathrm{l}^{10}$ proposed a modification of the emulsification-diffusion method (EDM) to prepare SLNs. In this modification, the author used a lipid instead of a preformed polymer. In general, a pre-emulsion is prepared; the internal phase contains the drug and the lipid which are solubilized in a partially water-miscible organic solvent, and the external phase is an aqueous solution of the stabilizer. This step can be performed with a cold or hot solvent, depending on the lipid's solubility in the organic phase. Then, the solvent diffuses into the external phase when water is added to the system, causing the formation of nanoparticles (NP). The rest of the solvent can be eliminated by the use of techniques such as cross-flow filtration, or under reduced pressure.

In addition to the advantages mentioned before, one of the most interesting features of SLNs is that they can improve the absorption of various drugs, making them an attractive alternative for the administration of substances with poor aqueous solubility and absorption. ${ }^{11-13}$

Cyclosporine (CyA) is a neutral, highly lipophilic undecapeptide obtained from Tolypoclaudium inflatum and Cylindrocarpus lucidum, and is used as an immunosuppressant drug to prevent transplant rejection. It is a Class II drug that has been studied in many pharmaceutical formulations due to its absorption and bioavailability problems. ${ }^{14-19}$ In recent years, SLNs containing CyA have been prepared using different preparation methods, optimized and studied by some research groups around the world. ${ }^{20-23}$ In this work EDM was used to prepare stable CyA-containing SLNs, showing an alternative to encapsulate this drug for the reason that CyA has exhibited absorption and bioavailability problems since it was launched into the market, and such lipidic carriers may represent a good alternative to improve these parameters. ${ }^{2,24,25}$ In the preformulation phase of this study, we performed the EDM at room temperature (RT) for Gelucire ${ }^{\circledR} 44 / 14$, and at controlled temperature $\left(65^{\circ} \mathrm{C}, \mathrm{CT}\right)$ for Compritol $^{\circledR} 888$ ATO. Only Gelucire ${ }^{\circledR}$ gave stable NP, so that systems with this lipid were characterized by their stability, particle size, Z-potential, morphology, thermal behavior, and entrapment efficiency. In the last phase of the study, in vitro drug release was evaluated, which is the first step of a further bioavailability study. Because of its adequate stability, this nanocarrier can be useful in further investigations for oral administration.

\section{Materials and methods Materials}

CyA was a contribution from Moléculas Finas, SA de CV (DF, Mexico). Glyceryl behenate (Compritol ${ }^{\circledR}$ ATO 888) and lauroyl macrogolglycerides (Gelucire ${ }^{\circledR} 44 / 14$ ) were provided by Lubrizol (Mexico City, Mexico). Polyvinyl alcohol (PVAL, Elvanol ${ }^{\circledR} 5105$ ) was obtained from Comercial Argento (DF, Mexico).

Distilled water was obtained from a Milli-Q station. Analytical grade ethyl acetate and methyl ethyl ketone (Fermont, Monterrey, NL, Mexico) were selected according to their low toxicity. All other chemical reagents were of analytical grade.

\section{Method of production of SLN}

According to previous data (Quintanar-Guerrero, 2005), ${ }^{10}$ stable SLNs were obtained with Gelucire ${ }^{\circledR} 44 / 14$ or Compritol® 888 ATO. Furthermore, the low toxicity and high biocompatibility of these materials are well known.

\section{Preparation of SLNs at RT}

The lipid used in this case was Gelucire ${ }^{\circledR} 44 / 14$, since it is soluble at RT in ethyl acetate, which was used as the internal phase in the pre-emulsification step. This partially water-miscible solvent was selected because in previous studies, stable particles of nanometric size were obtained. In this approach, at RT the amount of CyA was evaluated as variable, since the optimal amount of lipid, the type and amount of stabilizer, and the stirring rate have been defined in a previous study. ${ }^{10,26}$ 
The solvent and water were mutually saturated for $10 \mathrm{~min}$ at RT in order to generate equilibrium between the two liquids. Variable amounts of CyA $(20,25,30,40,60$, 120 , and $200 \mathrm{mg}$ ) and $400 \mathrm{mg}$ of lipid (Gelucire ${ }^{\circledR} 44 / 14$ ) were weighted.

The drug and lipid were dissolved in $20 \mathrm{~mL}$ of watersaturated solvent, which were emulsified with $40 \mathrm{~mL}$ of solvent-saturated aqueous solution containing $5 \% \mathrm{w} / \mathrm{v}$ of PVAL, using a mechanical stirrer (Caframo ${ }^{\circledR}$ RZR-1; Ontario, Canada; propeller: PR 31; Heidolph ${ }^{\circledR}$, Schwabach, Germany) at $1,800 \mathrm{rpm}$ for $10 \mathrm{~min}$. Then, $160 \mathrm{~mL}$ of water (dilution medium) were added to allow the solvent to diffuse into the external phase, thus causing the aggregation of the lipid and the subsequent formation of SLNs. Finally, the solvent was eliminated from the sample by vacuum distillation at $30^{\circ} \mathrm{C}$ and $70 \mathrm{mmHg}$. The remaining stabilizer and possible un-entrapped drug was removed by ultracentrifugation at 30,000 rpm for 50 min $\left(\right.$ Beckman $^{\circledR}$ Optimal LE-80K, CA, USA).

In this same way, empty SLNs and batches containing only CyA were prepared. All batches were produced in triplicate and the average size was immediately measured.

\section{Preparation of SLNs at CT}

In this case, we used $\mathrm{Compritol}^{\circledR}$ for particle preparation, and heating was required to dissolve the lipid; therefore, keeping both phases at a $\mathrm{CT}\left(65^{\circ} \mathrm{C}\right.$ that is lower than lipid's melting point) during the entire process was a crucial factor to obtain a system with good characteristics. In general, $200 \mathrm{mg}$ of lipid were weighted and dissolved in $20 \mathrm{~mL}$ of water-saturated solvent (methyl ethyl ketone). Variable amounts of CyA $(5,6,8$, and $10 \mathrm{mg})$ were added. This phase was emulsified with $40 \mathrm{~mL}$ of solvent-saturated aqueous solution containing $5 \% \mathrm{w} / \mathrm{v}$ PVAL, using a mechanical stirrer at 1,400 rpm for $10 \mathrm{~min}$. Afterwards, $160 \mathrm{~mL}$ of water were added in order to cause the solvent diffusion to the continuous phase and to start the lipid aggregation and formation of NPs. Vacuum distillation was used to eliminate the solvent. PVAL and/ or any remaining drug were removed in the same way as described above. Also empty SLN were prepared. Each batch was prepared in triplicate, and the average size was evaluated.

\section{Characterization of the systems}

\section{Particle size analysis}

The average size was determined by the dynamic light scattering technique (Coulter ${ }^{\circledR}$ N4, CA, USA). Each measurement was obtained at a $90^{\circ}$ fixed-angle for $180 \mathrm{~s}$, at $25^{\circ} \mathrm{C}$, and the laser light wavelength $(\mathrm{He} / \mathrm{Ne}, 10 \mathrm{~mW})$ was set at $678 \mathrm{~nm}$. A digital correlator was used to analyze the scattering intensity data under a unimodal analysis mode. All dispersions were diluted with distilled water until the light scattering signal (reported as counts per second) of the particles in suspension was within the instrument's sensitivity range. All batches prepared were measured in triplicate. Also, the macroscopic aspect of the systems was followed for six months in order to detect any instability signs and these results were corroborated with the information obtained in every analysis by dynamic light scattering technique.

\section{Z-potential}

Dispersions were diluted (1:10) with filtered water $(0.22 \mu \mathrm{m}$ pore). The electrophoretic mobility was transformed into Z-potential by applying the Smoluchowski approximation. Measurements were made in triplicate (Malvern Instruments ${ }^{\circledR} \mathrm{NS}$ ZEN 3600, Worcestershire, UK) at $25^{\circ} \mathrm{C}$ in a capillary cell.

\section{Scanning electron microscopy (SEM)}

After removing the excess stabilizer in the sample by two centrifugations $(30,000 \mathrm{rpm} / 50 \mathrm{~min})$ and following particle resuspension in water, a few drops of the dispersion were placed on a slab and dried under vacuum at RT. A Sputter Coater $^{\circledR}$ JFC-1100 (JEOL, Tokyo, Japan) was used to coat the dried samples with gold ( $20 \mathrm{~nm}$ thickness), placing them onto stubs. Finally, the samples were observed under a JSM- $6400^{\circledR}$ SEM (JEOL, Tokyo, Japan).

\section{Differential scanning calorimetry (DSC)}

DSC measurements were carried out on the following samples: a) CyA; b) Gelucire ${ }^{\circledR} 44 / 14$; c) PVAL; d) physical mixtures of CyA-Gelucire $^{\circledR}$ (40, 80, and $200 \mathrm{mg}$ of CyA with $400 \mathrm{mg}$ of Gelucire $^{\circledR}$ in all cases); e) physical mixtures of CyA-PVAL (20, 80, and $200 \mathrm{mg}$ of drug with $100 \mathrm{mg}$ of PVAL in all cases); f) empty SLNs; g) batches containing only CyA (without lipid); and h) batches with variable amounts of CyA (20, 60 , and $200 \mathrm{mg}$ ) and a constant amount of Gelucire ${ }^{\circledR}(400 \mathrm{mg})$. Batches containing only CyA were prepared in order to check if drug nanocrystals were formed. All samples were dried and stored in a desiccator at RT and standard humidity. Quantities between 3-6 mg of each sample were weighted. DSC studies were performed in a DSC Q $10^{\circledR}$ (TA Instruments, DE, USA), using aluminum open pans. The heating rate was $10^{\circ} \mathrm{C} / \mathrm{min}$, with a temperature range of $0-230^{\circ} \mathrm{C}$ and a $50 \mathrm{~mL} / \mathrm{min}$ nitrogen flow. Indium was used as the reference standard to check the calibration of the device. 


\section{Stabilizer quantification}

The remaining amount of PVAL in SLNs was determined by a colorimetric method, based on the formation of a stable complex with iodine in the presence of boric acid. ${ }^{27}$ After lyophilizing an SLN dispersion (30 mg of drug with $400 \mathrm{mg}$ of Gelucire ${ }^{\circledR}$ ), about $10 \mathrm{mg}$ of the sample were weighted and $5 \mathrm{~mL}$ of ethanol were added. The sample was stirred for $24 \mathrm{~h}$ at RT. Then, $3 \mathrm{~mL}$ of distilled water were added and stirring was continued for $3 \mathrm{~h}$. Samples were filtered through a membrane $(0.22 \mu \mathrm{m})$ and the volume was adjusted to $10 \mathrm{~mL}$ with distilled water. Then $5 \mathrm{~mL}$ were taken from this solution and mixed with $2 \mathrm{~mL}$ of $0.65 \mathrm{M}$ boric acid and $1 \mathrm{~mL}$ of an iodine solution ( $0.05 \mathrm{M}$ iodine and $0.15 \mathrm{M}$ potassium iodide). The analysis was performed in triplicate. The absorbance of the resulting samples was measured at $640 \mathrm{~nm}$ (Varian ${ }^{\circledR}$ Cary IE 9531003 Spectrophotometer, Australia) and this result was interpolated in a calibration curve for PVAL (linear within the range of $\left.5-50 \mu \mathrm{g} / \mathrm{mL}, \mathrm{R}^{2}=0.9993\right)$. A solution composed of $5 \mathrm{~mL}$ of water, $2 \mathrm{~mL}$ of boric acid solution, and $1 \mathrm{~mL}$ of iodine solution was used as blank.

\section{Drug loading and entrapment efficiency}

Three batches with $400 \mathrm{mg}$ of Gelucire ${ }^{\circledR} 44 / 14$ and $30 \mathrm{mg}$ of CyA were prepared at RT as described above and lyophilized, the reason for preparing this batch is because particle size had little variation and Z-potential had the highest value. A combination of $20 \mathrm{mg}$ of lyophilized NP and $2 \mathrm{~mL}$ of ethanol were put into a beaker and were subsequently agitated for $24 \mathrm{~h}$. After filtering the samples, 6,000 $\mathrm{nL}$ were applied on a reverse-phase plate to perform the determination by high performance thin layer chromatography (HPTLC); mobile phase acetonitrile-water $(65: 35)+1 \%$ triethylamine, saturation time $15 \mathrm{~min}$, absorbance-reflection mode, deuterium lamp, $\lambda=240 \mathrm{~nm}$ ). The results were interpolated in a calibration curve which was linear within the range of $2-10 \mu \mathrm{g}$, $\mathrm{R}^{2}=0.9950$. The analysis was made in triplicate.

Equations (1) and (2) were applied to calculate drug loading (DL) and entrapment efficiency (EE):

$$
\begin{aligned}
\operatorname{DL}(\%)= & \frac{\text { amount of CyA in lyophilized NPs }}{\text { amount of lyophilized NPs }} \times 100 \\
\operatorname{EE}(\%)= & \frac{\mathrm{DL}(\%)}{\% \text { of the initial CyA content } \mathrm{x}} \times 100 \\
& (1-\text { fraction of residual PVAL })
\end{aligned}
$$

It is important to introduce correction factor $1 /(1$-fraction of residual PVAL) to avoid an overestimation of the EE, due to the fact that during the SLN formation process, a certain amount of stabilizer remains on the carrier's surface. The initial CyA content is the theoretical CyA loading in the batch.

\section{In vitro release}

A batch with $50 \mathrm{mg}$ of CyA and $400 \mathrm{mg}$ of Gelucire ${ }^{\circledR}$ was prepared as described previously and placed in a glass flask containing $10 \mathrm{~mL}$ of sodium lauryl sulfate $(0.5 \% \mathrm{w} / \mathrm{v}$ aqueous solution). The stoppered flask was kept at $37^{\circ} \mathrm{C}$ in a water bath. Then, $2 \mathrm{~mL}$ samples were withdrawn from the medium at $5,15,30,45$, and $60 \mathrm{~min}$, and then at 2,3 , and $4 \mathrm{~h}$, replacing the medium with a fresh one at the same temperature and introducing it through the same filter holder; in this way sink conditions were maintained during the test. The samples were withdrawn through a syringe adapted to a filter holder (Swinnex ${ }^{\circledR} 13$; Millipore, MA, USA) using Isopore ${ }^{\mathrm{TM}}$ membrane filters $(0.1 \mu \mathrm{m}, \mathrm{VCTP}$; Millipore). Residual water was removed from each sample under reduced pressure, and then $2 \mathrm{~mL}$ of ethanol were added. Following stirring ( $1 \mathrm{~h})$, the samples were filtered and quantified by HPTLC, as mentioned before.

\section{Turbidity measurement during in vitro release}

Turbidity $(\tau)$ was measured in each sample taken during the release experiment, as a complementary test to follow up changes in particle size of SLNs in the medium with surfactant. The sample was placed in a quartz cell and was analyzed at $360 \mathrm{~nm}$. Absorbance is related to $\tau$ by the next equation: ${ }^{28}$

$$
\tau=\frac{2.303 \mathrm{~A}}{l}
$$

where $l$ is the optical length $(1 \mathrm{~cm})$, and $\mathrm{A}$ is the absorbance.

\section{Results}

With both methods (at RT and CT), it was possible to obtain SLNs, unless there was a statistical difference in size for empty NP, $P<0.05$ (Table 1 ).

During particle size evaluation on batches with Compritol $^{\circledR}$, a relatively rapid destabilization of the systems was evident, even with a lower CyA content (5 mg), leading to the presence of macroscopic agglomerates. The initial Z-potential $(\mathrm{t}=0)$ was under $30 \mathrm{mV}$ in all batches with $\mathrm{Compritol}^{\circledR}$, and was associated with a low dispersion stability. Also, a higher particle size variation in SLN batches compared with Gelucire ${ }^{\circledR}$ was observed. Based on these results, it was concluded that Compritol $^{\circledR}$ is not adequate to produce CyA-SLNs, due to poor stability related problems. 
Table I Mean particle size of empty SLNs prepared at RT $\left(\right.$ Gelucire $\left.^{\circledR}=400 \mathrm{mg}\right)$ and at CT $\left(\right.$ Compritol $\left.^{\circledR}=200 \mathrm{mg}\right)$, with $5 \% \mathrm{w} / \mathrm{v}$ PVAL; $n=3$

\begin{tabular}{lll}
\hline & \multicolumn{2}{l}{$\begin{array}{l}\text { Mean particle size }(\mathbf{n m}) \text { and } \\
\text { polydispersity index }\end{array}$} \\
\cline { 2 - 3 } & Gelucire $^{\circledR}$ & Compritol $^{\circledR}$ \\
\hline Batch I & $280.0[0.220]$ & $789.0[0.524]$ \\
Batch 2 & $281.3[0.283]$ & $756.9[0.509]$ \\
Batch 3 & $280.8[0.316]$ & $734.5[0.481]$ \\
Mean & $280.7^{\mathrm{a}}$ & $760.1^{\mathrm{a}}$ \\
Standard deviation $(\sigma)$ & 0.65 & 27.30 \\
\hline
\end{tabular}

Notes: ${ }^{a}$ Exists statistical difference between means, $P<0.05$; PDI values between brackets.

Table 2 summarizes the composition and some characterization results obtained for all the systems prepared with Gelucire $^{\circledR}$.

In the case of SLNs prepared with Gelucire ${ }^{\circledR}$, the macroscopic evaluation of the systems showed that the time of appearance of abundant and bigger agglomerates was shorter as the drug content in the dispersion increased ( $\geq 60 \mathrm{mg}$ CyA) (Table 2).

SEM showed that all batches evaluated had a solid matrix structure without crystal formation (Figure 1 A-D).

It was evident that alongside time the particles started a process of aggregation (Figure 1C and 1D), which could be confirmed with measurements of particle size (dynamic light scattering and visual appearance).

A calorimetric analysis was performed on free samples of Gelucire ${ }^{\circledR}$, CyA, PVAL, physical mixtures (CyA-Gelucire and PVAL-CyA), and loaded and unloaded SLNs in order to determine the physical state of the drug and lipid, and to find out whether there were any interactions between them. Figures 2, 3 and 4 show the thermograms obtained. Figure 2 shows the thermal events of raw materials. Enthalpy of fusion of the drug is at $128.5^{\circ} \mathrm{C}$. The first peak of Gelucire ${ }^{\circledR}$ at $40.6^{\circ} \mathrm{C}$ is attributable to the fusion of the major proportion of glycerides, and the endotherm at $136.88^{\circ} \mathrm{C}$ corresponds to minority components of the mixture of glycerides. For PVAL the thermal events corresponding to its glass transition are shown. The physical mixtures analyzed are shown in Figure 3. For physical mixtures CyA-Gelucire ${ }^{\circledR}$ we observed any peak corresponding to crystal melting of drug, and no changes are observed in enthalpy fusion of Gelucire ${ }^{\circledR}$ (around $40^{\circ} \mathrm{C}$ in the three physical mixtures). An effect of drug amount is observed in physical mixtures CyA-PVAL; as drug increases in the physical mixture it is more evident its melting point. Thermal events of all batches analyzed are shown in Figure 4. None of them showed the peak corresponding to crystal melting of the drug and Gelucire ${ }^{\circledR}$ peak $\left(40.6^{\circ} \mathrm{C}\right)$ showed less sharpness at $\mathrm{t}=0$ with high drug amounts in the SLN batches, suggesting that CyA somehow affected lipid's structure.

The in vitro release results and the turbidity measurement are shown in Figure 5.

The remaining PVAL quantified in the formulation Gelucire $^{\circledR}$-CyA $(400: 30 \mathrm{mg})$ was $4.37 \% \pm 0.08(\mathrm{n}=3)$. The residual PVAL for polymeric NPs is reported to be proximately $2 \%-4 \%,{ }^{29}$ so it can be concluded that purification process of the dispersion was adequate.

In Table 2 the results for encapsulation efficiency are shown. In all systems these values were greater than $92 \%$.

\section{Discussion}

As was stated before, a relatively rapid destabilization was evident during particle size evaluation on batches with Compritol ${ }^{\circledR}$, even with a lower CyA content (5 mg), leading to the presence of macroscopic agglomerates at the second day of analysis. Comparing the quantity of drug

Table 2 Composition of the formulations, percentage (w/w) of CyA with respect to the weight of lipid, mean particle size, Z-potential and probable day of aggregation of SLNs prepared at RT (Gelucire ${ }^{\circledR}$ ) with 5\% w/v PVAL

\begin{tabular}{llllllll}
\hline System & $\begin{array}{l}\text { Gelucire } \\
(\mathbf{m g})\end{array}$ & $\begin{array}{l}\text { CyA } \\
(\mathbf{m g})\end{array}$ & $\begin{array}{l}\text { \% CyA } \\
(\mathbf{w} / \mathbf{w})\end{array}$ & $\begin{array}{l}\text { Particle size } \\
(\mathbf{n m})^{\mathbf{a}}\end{array}$ & $\begin{array}{l}\text { Z-potential } \\
(\mathbf{m V})^{\mathbf{a}}\end{array}$ & $\begin{array}{l}\text { Day of visible } \\
\text { aggregation }\end{array}$ & $\begin{array}{l}\text { Encapsulation } \\
\text { efficiency }(\%)\end{array}$ \\
\hline Empty SLN & 400 & 0 & 0.00 & $276.6 \pm 5[0.34]$ & $23.70 \pm 0.034$ & - & - \\
Batches containing & 0 & 40 & 0.00 & $2510.0 \pm 7[0.87]$ & $22.50 \pm 0.196$ & 11 & - \\
only CyA & & & & & & & \\
A & 400 & 20 & 5.00 & $256.4 \pm 1[0.36]$ & $22.80 \pm 0.014$ & 69 & 99.18 \\
B & 400 & 25 & 6.25 & $346.1 \pm 3[0.28]$ & $33.07 \pm 0.024$ & 80 & 99.15 \\
C & 400 & 30 & 7.50 & $310.5 \pm 3[0.22]$ & $39.50 \pm 0.150$ & 64 & 99.13 \\
D & 400 & 40 & 10.00 & $248.3 \pm 5[0.15]$ & $28.91 \pm 1.257$ & 78 & 99.02 \\
E & 400 & 50 & 12.50 & $320.8 \pm 7[0.18]$ & $30.11 \pm 1.361$ & 20 & 12 \\
F & 400 & 60 & 15.00 & $459.3 \pm 1[0.48]$ & $30.50 \pm 0.032$ & 12 & 98.45 \\
G & 400 & 120 & 30.00 & $375.7 \pm 1[0.65]$ & $34.12 \pm 0.048$ & 4 & 98.19 \\
H & 400 & 200 & 50.00 & $478.3 \pm 1[0.73]$ & $30.13 \pm 3.841$ & 2 & 95.26 \\
\hline
\end{tabular}

Notes: aReported as mean \pm standard deviation; $n=3$. 

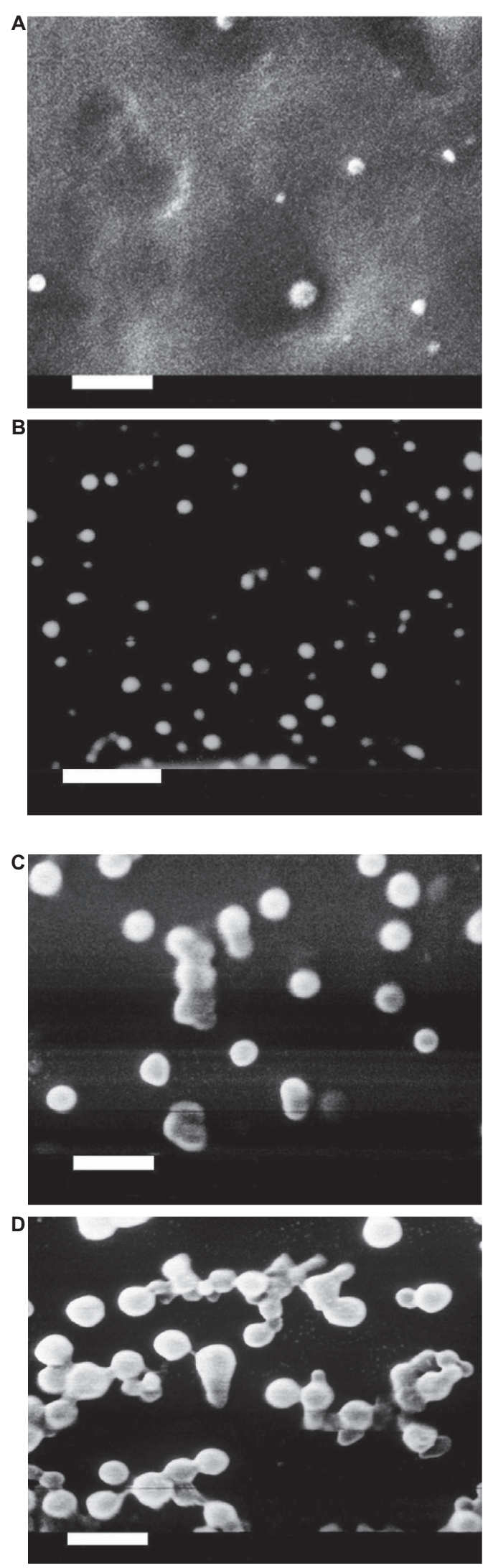

Figure I Scanning electron micrographs of loaded Gelucire ${ }^{\circledR}$ 44/14 SLNs with different theoretical loadings (bar $=1 \mu \mathrm{m})$. A) CyA-Gelucire ${ }^{\circledR}(20: 400 \mathrm{mg} ; 5 \%$ CyA) $\mathrm{t}=0$; B) CyA-Gelucire ${ }^{\circledR}(40: 400 \mathrm{mg} ; 10 \%$ CyA $) \mathrm{t}=0$; C) CyA-Gelucire ${ }^{\circledR}(30: 400 \mathrm{mg}$; $7.5 \%$ CyA) $\mathrm{t}=0$; D) CyA-Gelucire ${ }^{\circledR}(30: 400$ mg; 7.5\% CyA) $\mathrm{t}=4$ months.

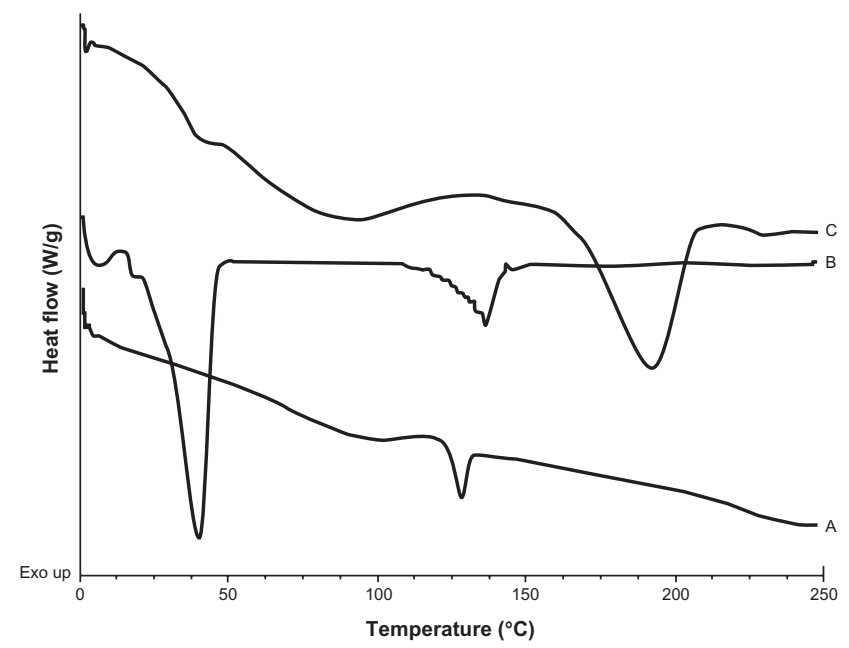

Figure 2 DSC thermograms of A) CyA; B) Gelucire ${ }^{\circledast} 44 /$ I4; C) PVAL.

that Compritol ${ }^{\circledR}$ SLNs can carry with that of Gelucire ${ }^{\circledR}$, it can be assumed that chemical composition (higher content of hydrophobic and longer chain length, $>83 \% \mathrm{C} 22$ ) and the high degree of crystallinity of the former could lead to drug expulsion from the NP easily. In this respect, Varia et $\mathrm{a}^{22}$ corroborate that chemical composition of the lipid has an important effect to incorporate drugs in SLNs; a lipid which is formed mainly by structurally similar molecules cannot accommodate big quantities of drug compared with a lipid which is a mixture of mono-, di- and triglycerides, and has the ability to offer many imperfections to incorporate the drugs.

When comparing the mean particle size of NP prepared with Gelucire ${ }^{\circledR}$ with that of NP prepared with Compritol ${ }^{\circledR}$ (Table 1), the former had a smaller size. This can be attributed to the complex mixtures of mono-, di-, and triglycerides that formed both materials; however, Gelucire ${ }^{\circledR}$ has a higher content of short hydrophilic chains [C8, C10, C12 (30\%-50\%), C14 (5\%-25\%), C18 (5\%-35\%)] than Compritol ${ }^{\circledR}[\mathrm{C} 16$, $\mathrm{C} 18, \mathrm{C} 20(<10 \%), \mathrm{C} 22(>83 \%), \mathrm{C} 24(<3 \%)]$. For this reason, the higher content of hydrophobic and longer chains in Compritol ${ }^{\circledR}$ may somehow hinder its dispersion in aqueous media, compared with Gelucire ${ }^{\circledR}$.

The initial Z-potential $(\mathrm{t}=0)$ was under $30 \mathrm{mV}$ in all batches with $\mathrm{Compritol}^{\circledR}$, and was associated with a low dispersion stability. Also, the higher particle size variation in SLN batches compared with Gelucire ${ }^{\circledR}$ was determinant to conclude that $\mathrm{Compritol}^{\circledR}$ was not adequate to produce CyA-SLNs, due to poor stability related problems.

The presence of bigger and abundant agglomerates in systems prepared with Gelucire ${ }^{\circledR}$ was more evident with DL $>10 \%$ and also the time of appearance of these agglomerates were developed in shorter time (Table 2). This 


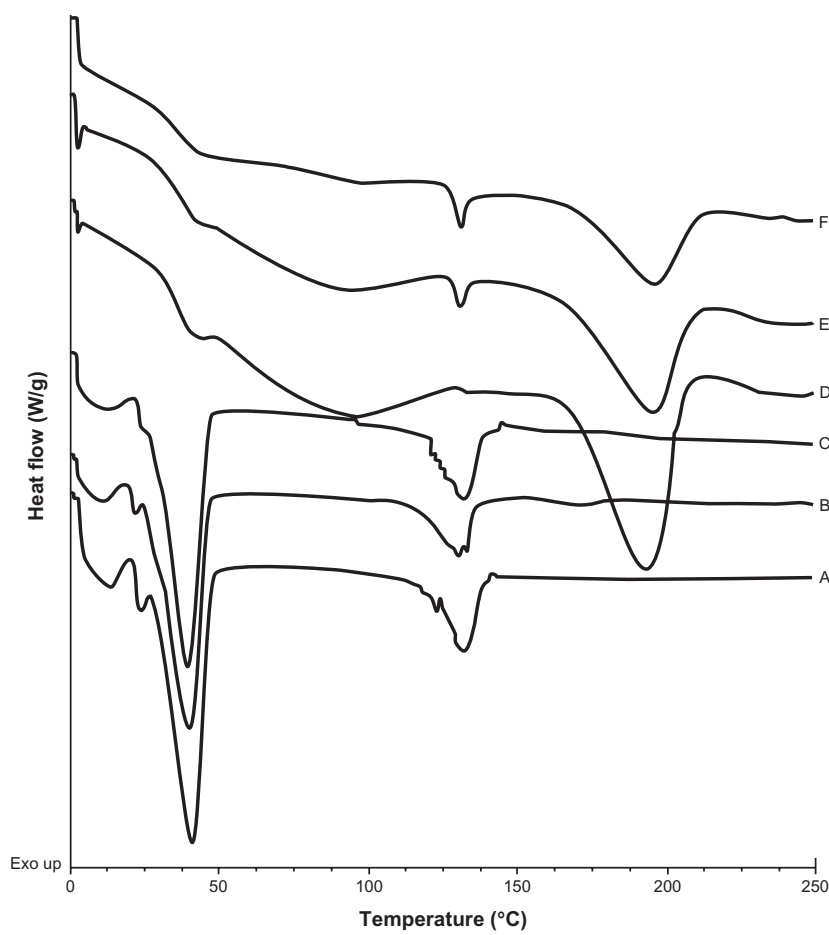

Figure 3 DSC thermograms of A) Physical mixture of CyA-Gelucire ${ }^{\circledR}$ (40:400 $\mathrm{mg} w / \mathrm{w})$; B) Physical mixture of CyA-Gelucire ${ }^{\circledR}(80: 400 \mathrm{mg} \mathrm{w} / \mathrm{w})$; C) Physical mixture of CyA-Gelucire ${ }^{\circledast}(200: 400 \mathrm{mg} w / \mathrm{w})$; D) Physical mixture of CyA-PVAL (20:100 mg w/w); E) Physical mixture of CyA-PVAL (80:100 mg w/w); and F) Physical mixture of CyA-PVAL (200:100 mg w/w).

effect may have been caused by a probable expulsion of the drug due to the lipid's partial rearrangement. It is well known that glycerides have three main polymorphs: $\alpha, \beta$ ' and $\beta$. Assuming that our NP were made from a material containing mono-, di-, and triglycerides (proportions: [C8, C10, $\mathrm{C} 12$ (30\%-50\%), C14 (5\%-25\%), C18 (5\%-35\%)]), it is possible to believe that, during storage, a part of the lipid matrix transformed from one polymorph into another, reducing the spaces in the matrix and causing the drug to come out. Several reports have described this behavior. ${ }^{1,30-32}$ Once the CyA molecules were outside or on the nanoparticle's surface, they started to interact inter- or intramolecularly, producing associations between them and causing a physical stability loss, although SEM studies did not confirm crystal deposition on SLN surface.

For the dispersions with $25 \mathrm{mg}$ of CyA, the Z-potential was higher than $30 \mathrm{mV}$ (Table 2), which is related to a complete electrostatic stabilization of particles in suspension, with a maximum value of $39.50 \mathrm{mV}$ for a CyA content of $30 \mathrm{mg}$. When the dispersion had more than $30 \mathrm{mg}$ of drug, the Z-potential did not show a specific trend. This effect may be explained by the superficial properties of the drug that make the molecules to be preferably oriented at the solid-liquid interface, causing a change in the net charge of

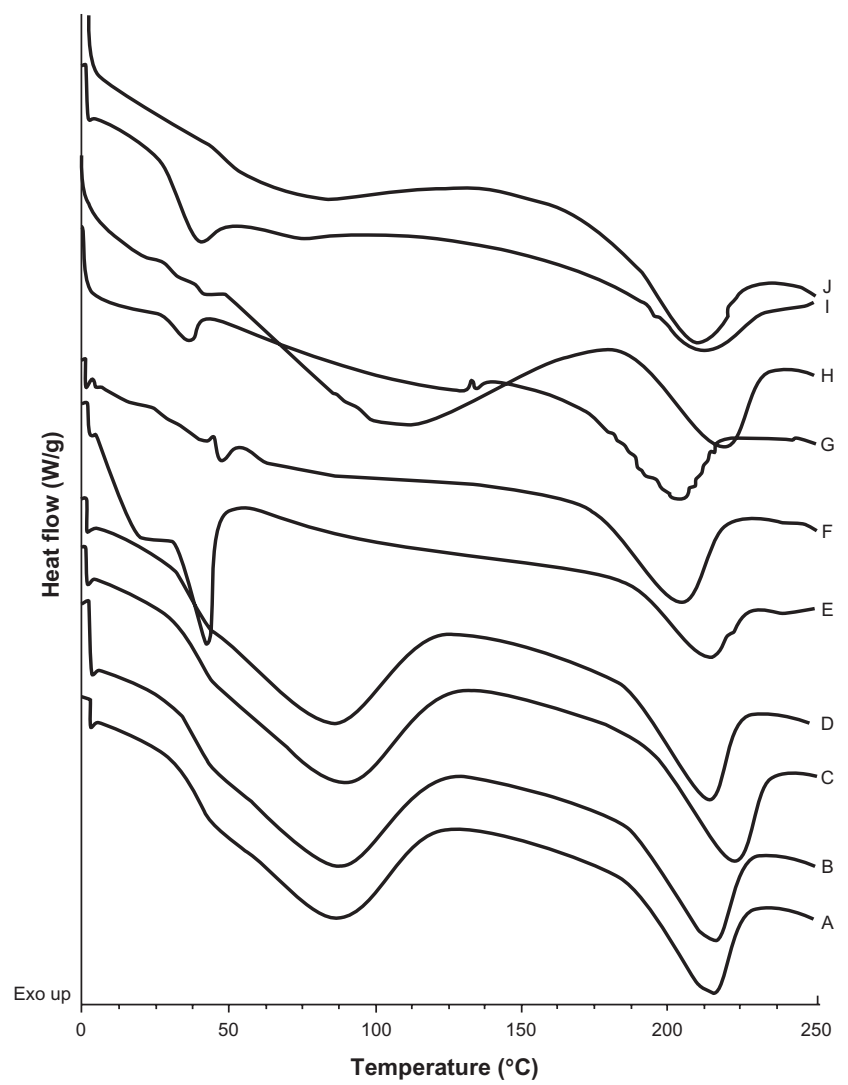

Figure 4 DSC thermograms of A) and B) batches prepared with CyA only, $t=0$ and $t=5$ months respectively; C) and D) empty SLNs; $t=0$ and $t=5$ months respectively; E) and F) SLNs with 5\% CyA (drug-lipid ratio 20:400 (w/w)), t $=0$ and $t=5.5$ months, respectively; $\mathrm{G}$ ) and $\mathrm{H}$ ) SLNs with 15\% CyA (drug-lipid ratio $60: 400(w / w)), t=0$ and $t=5.5$ months, respectively; l) and J) SLNs with $50 \%$ CyA (drug-lipid ratio $200: 400(\mathrm{w} / \mathrm{w})$ ), $\mathrm{t}=0$ and $\mathrm{t}=5.5$ months, respectively.

the particle. We may have expected a direct increase of the charge for a higher drug content, but this behavior was not observed, probably because CyA can be located inside and/or outside the NP; in this respect, Lechuga-Ballesteros et $\mathrm{al}^{33}$ have recently reported that CyA can form a liquid crystal structure in repeated layers.

After three months of storage, the Z-potential decreased by almost $10 \mathrm{mV}$ for all dispersions prepared with Gelucire ${ }^{\circledR}$. This fact can be explained by the partial and gradual arrangement of the lipid, and by the ejection of small amounts of CyA. In the latter case, the CyA molecules outside the NP may induce the formation of the aforementioned structures, thus changing the net charge of the particle. Also, the production method may provide another explanation. Following dispersion production, the molecules have not a specific arrangement, they are randomly arrayed all over the nanoparticle; however, CyA molecules may acquire a more ordered distribution in space over time ${ }^{33}$ which can change the surface charge.

SEM showed that all batches evaluated had a solid matrix structure without crystal formation (Figure 1A-1C) and alongside time showed the aggregation of NP (Figure 1D); 


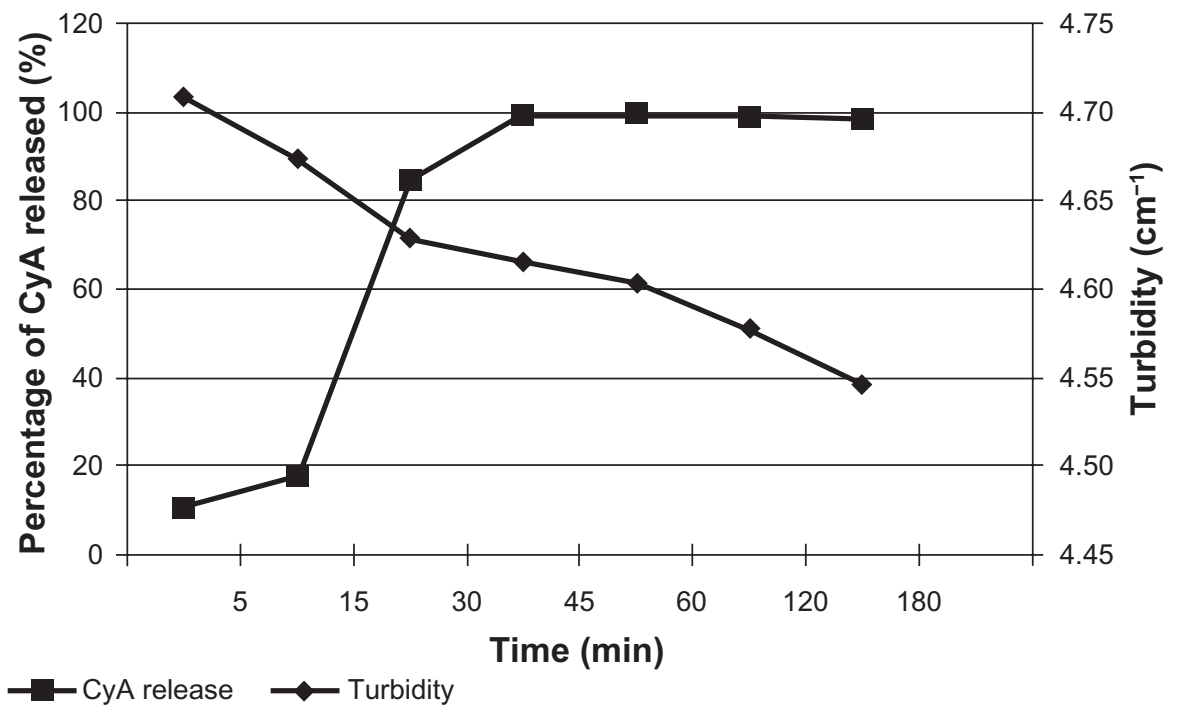

Figure $\mathbf{5}$ In vitro release of CyA and turbidity changes during this experiment.

this fact can be explained by changes in the particles' charge by the ejection of small amounts of the drug or by the rearrangement of CyA molecules to a more ordered state after production of SLNs.

Thermograms are shown in Figure 2, 3, and 4. An endotherm at $128.5^{\circ} \mathrm{C}$ was shown for pure CyA; this event was not observed for batches containing only CyA $(40 \mathrm{mg})$ at $\mathrm{t}=0$ and $\mathrm{t}=$ five months (Figure 4A and 4B), and it may be related to a low drug amount in the sample, because in the CyA-PVAL physical mixtures analyzed, the endotherm corresponding to the melting process of the drug could only be observed from $80 \mathrm{mg}$ of CyA (Figure 3E). Melting point of drug in these physical mixtures did not change (around $128^{\circ} \mathrm{C}$ ).

DSC thermograms of empty SLNs at $\mathrm{t}=0$ and $\mathrm{t}=$ five months did not show any change in thermal events (Figure 4C and 4D). It is possible that hydroxyl groups of glycerides can form hydrogen bonds with hydroxyl groups of PVAL, avoiding lipid crystallization. In the batches of SLN containing 5,15 , and $50 \%$ of drug $(20,60$, and $200 \mathrm{mg})$, there was no endothermic peak corresponding to crystal melting, even at five months, suggesting the presence of a molecular dispersion of the drug and lipid. Furthermore, it can be assumed that CyA maintained an amorphous or disordered crystalline phase of a molecular dispersion or a solid solution state in the lipid matrix after the process, as reported previously by our group for triclosan-containing polymeric NP, ${ }^{29}$ and for CyA-loaded SLNs. ${ }^{21}$

Thermograms of CyA-PVAL physical mixtures with 80 and $200 \mathrm{mg}$ of drug (Figure 3E and 3F) showed the endothermic peak corresponding to the melting of $\mathrm{CyA}$; thus, the absence of an endotherm in the thermogram of the batch containing $200 \mathrm{mg}$ of drug (Figure 4I and 4J) supports our assumption regarding the formation of a molecular dispersion.

Another important event is that observed for the endotherm associated to Gelucire ${ }^{\circledR}$ melting. At $t=0$, this endotherm was sharper than at five months (Figure 4E-4J); in fact, it was not clearly detected at this time point. During the SLN formation process, the solvent diffuses from the emulsion's globules; the drug and lipid aggregate randomly, possibly leaving regions of free lipid with a high order or crystalline state. The drug and lipid may interact over time, and some CyA molecules may be inserted between the glyceride chains, ${ }^{21}$ reducing the crystalline state of the lipid. On the other hand, it was noteworthy that the Gelucire ${ }^{\circledR}$ peak $\left(40.6^{\circ} \mathrm{C}\right)$ showed less sharpness at $\mathrm{t}=0$ with high drug amounts in the SLN batches, suggesting first that CyA was encapsulated into the NPs and second, that the drug had an important impact on the lipid's structure. This behavior is similar to that reported in model lipidic membranes, in which the peptide is considered as a "defect" in the lipid bilayer, which can be randomly distributed in the hydrocarbon region, affecting lipid interactions due to the electrostatic charges and to the geometry of the guest molecule. ${ }^{34,35}$

An immediate release was observed (Figure 5); 99.60\% of CyA was released from the SLN at $45 \mathrm{~min}$, indicating the presence of an amorphous structure of the lipid and maybe the existence of CyA molecules on the NP surface, which allows a rapid dissolution and possibly higher loadings.

Turbidity measurement (Figure 5) is an indirect way to determine changes of particle size in the dispersion once 
it enters the biological fluids. In this experiment, turbidity decreased over time due to the reduction of entire nanospheres owing to the action of the dissolution medium.

The great advantage of using Gelucire ${ }^{\circledR}$, composed of a mixture of mono-, di-, and triglycerides with different chain lengths, is that the matrix may have more imperfections in which higher quantities of drug can accommodate, in contrast with the reduced spaces provided by structurally similar molecules (for example tripalmitin and tristearin). This feature was also important to achieve high EE, $>92 \%$ (Table 2). Moreover, the possibility of an amorphous state in the lipidic matrix could be responsible for the amount of drug encapsulated. High EE were also found using different preparation methods of SLNs. ${ }^{20,22,23}$

\section{Conclusion}

With the EDM, it was possible to obtain Gelucire ${ }^{\circledR}$ NP with a good stability. Although NP with Compritol $^{\circledR}$ were also prepared, the significant instability issues at the first stages of storage made this material inadequate to obtain such carriers.

As the CyA content increased in Gelucire ${ }^{\circledR}$ NP, variations in size were more evident and particle size increased over time in all batches. The Z-potential decreased $10 \mathrm{mV}$ after three months in SLNs prepared with Gelucire ${ }^{\circledR}$. The formation of molecular dispersions was evident, and it was shown that CyA affected the lipid's structure by a mechanism still unknown, probably by the ability of these molecules to form a liquid crystal with a repeated-layer structure. High EE was achieved ( $>92 \%)$. CyA release from SLNs was relatively fast $(99.60 \%$ in $45 \mathrm{~min}$ ), in association with a rapid dissolution due to the presence of many imperfections in lipid structure. We are still working on the evaluation of these carriers, since they may have a great impact on CyA's bioavailability profile as a result of a dissolution improvement because of the imperfections of the lipidic matrix.

\section{Acknowledgment}

The authors are grateful to Mr Rodolfo Robles for his technical assistance with the scanning electron microscope.

\section{Disclosure}

The authors report no conflicts of interest in this work.

\section{References}

1. Muller RH, Radtke M, Wissing SA. Nanostructured lipid matrices for improved microencapsulation of drugs. Int J Pharm. 2002;242(1-2): 121-128.

2. Muller RH, Keck CM. Challenges and solutions for the delivery of biotech drugs - a review of drug nanocrystal technology and lipid nanoparticles. J Biotech. 2004;113(1-3):151-170.
3. Trotta M, Cavalli R, Trotta C, Bussano R, Costa L. Electrospray technique for solid lipid-based particle production. Drug Dev Ind Pharm. 2010;36(4):431-438.

4. Battaglia L, Gallarate M, Cavalli R, Trotta M. Solid lipid nanoparticles produced through a coacervation method. J Microencaps. 2010;27(1): 78-85.

5. Singh S, Dobhal AK, Jain A, Pandit JK, Chakraborty S. Formulation and evaluation of solid lipid nanoparticles of a water soluble drug: zidovidine. Chem Pharm Bull. 2010;58(5):650-655.

6. del Pozo-Rodríguez A, Delgado D, Solinis MA, et al. Solid lipid nanoparticles as potential tools for gene therapy: in vivo protein expression after intravenous administration. Int J Pharm. 2010;385(1-2): $157-162$.

7. Varshosaz J, Minayian M, Moazen E. Enhancement of oral bioavailability of pentoxifylline by solid lipid nanoparticles. J Liposome Research. 2010;20(2):115-123.

8. Hu L, Jia H, Luo Z, Liu C, Xing Q. Improvement of digoxin oral absorption in rabbits by incorporation into solid lipid nanoparticles. Pharmazie. 2010;65(2):110-113.

9. Mehnert W, Mader K. Solid lipid nanoparticles. Production, characterization, and applications. Adv Drug Deliv Rev. 2001;47(2-3):165-196.

10. Quintanar-Guerrero D, Tamayo-Esquivel D, Ganem-Quintanar A, Allémann E, Doelker E. Adaptation and optimization of the emulsificationdiffusion technique to prepare lipidic nanospheres. Eur J Pharm Sci. 2005;26(2):211-218

11. Tamayo-Esquivel D, Ganem-Quintanar A, Martinez AL, NavarreteRodriguez M, Rodriguez-Romo S, Quintanar-Guerrero D. Evaluation of the enhanced oral effect of omapatrilat-monolein nanoparticles prepared by the emulsification-diffusion method. J Nanosci Nanotechnol. 2006;6(9-10):3134-3138.

12. Yi Fan L, Da Wei C, Li Xiang R, Xiu Li Z, Jing Q. Solid lipid nanoparticles for enhancing vinpocetine's oral bioavailability. J Control Release. 2006;114(1):53-59.

13. Nan Z, Qineng P, Guihua H, Wenfang X, Yanna Ch, Xiuzhen H. Lectinmodified solid lipid nanoparticles as carriers for oral administration of insulin. Int J Pharm. 2006;327(1-2):153-159.

14. Kovarik JM, Mueller EA, van Bree JB, Tetzloff W, Kutz K. Reduced inter- and intra-individual variability in cyclosporine pharmacokinetics from a microemulsion formulation. J Pharm Sci. 1994;83(3): 444-446.

15. Molpeceres J, Guzman M, Aberturas MR, Chacon M, Berges L. Application of central composite designs to the preparation of polycaprolactone nanoparticles by solvent displacement. J Pharm Sci. 1996;85(2):206-213.

16. Tarr BD, Yalkowsky SH. Enhanced intestinal absorption of cyclosporine in rats through the reduction of emulsion droplet size. Pharm Res. 1989;6(1):40-43.

17. Sanchez A, Vila-Jato JL, Alonso MJ. Development of biodegradable microspheres and nanospheres for the controlled release of cyclosporine A. Int J Pharm. 1993;99(2-3):263-273.

18. Guzman M, Molpeceres J, Garcia F, Aberturas MR, Rodriguez M. Formation and characterization of cyclosporine-loaded nanoparticles. J Pharm Sci. 1993;82(5):498-502.

19. Al-Angary AA, Bayomi MA, Khidr SH, Al-Meshal MA, Al-Dardiri M. Characterization, stability, and in vivo targeting of liposomal formulations containing cyclosporin. Int J Pharm. 1995; 114(2):221-225.

20. Muller RH, Runge S, Ravelli V, Mehnert W, Thunemann AF, Souto EB. Oral bioavailability of cyclosporine: solid lipid nanoparticles $\left(\right.$ SLN $\left.^{\circledR}\right)$ versus drug nanocrystals. Int J Pharm. 2006;317(1):82-89.

21. Muller RH, Runge SA, Ravelli V, Thunemann AF, Mehnert W, Souto EB. Cyclosporine-loaded solid lipid nanoparticles $\left(\mathrm{SLN}^{\circledR}\right)$ : drug-lipid physicochemical interactions and characterization of drug incorporation. Eur J Pharm Biopharm. 2008;68(3):535-544.

22. Varia JK, Dodiya SS, Sawant KK. Cyclosporine A loaded solid lipid nanoparticles: optimization of formulation, process variable, and characterization. Curr Drug Del. 2008;5(1):64-69. 
23. Gokce EH, Sandri G, Bonferoni MC, et al. Cyclosporine A loaded SLNs: evaluation of cellular uptake and corneal cytotoxicity. Int J Pharm. 2008;364(1):76-86.

24. Hanafy A, Spahn-Langguth H, Vergnault G, et al. Pharmacokinetic evaluation of oral fenofibrate nanosuspensions and SLN in comparison to conventional suspensions of micronized drug. Adv Drug Deliv Rev. 2007;59(6):419-426.

25. Manjunath K, Venkateswarlu V. Pharmacokinetics, tissue distribution, and bioavailability of clozapine solid lipid nanoparticles after intravenous and intraduodenal administration. J Control Release. 2005;107(2): 215-228.

26. Tamayo-Esquivel D. (2005). Preparación de dispersiones lipídicas de talla submicrónica por medio del método de emulsificación difusión, Tesis de Maestría, Universidad Nacional Autónoma de México.

27. Allemann E, Doelker E, Gurny R. Drug loaded poly(lactic acid) nanoparticles produced by a reversible salting-out process, purification of an injectable dosage form. Eur J Pharm Biopharm. 1993;39(1):13-18.

28. Quintanar-Guerrero D, Allemann E, Doelker E, Fessi H. A mechanistic study of the formation of polymer nanoparticles by the emulsiondiffusion technique. Colloid Polym Sci. 1997;275(7):640-647.

29. Pinon-Segundo E, Ganem-Quintanar A, Alonso-Perez V, QuintanarGuerrero D. Preparation and characterization of triclosan nanoparticles for periodontal treatment. Int J Pharm. 2005;294(1-2):217-232.
30. Muller RH, Mader K, Gohla S. Solid lipid nanoparticles (SLN) for controlled drug delivery - a review of the state of the art. Eur J Pharm Biopharm. 2000;50(1):161-177.

31. Westesen K, Bunjes H, Koch MHJ. Physicochemical characterization of lipid nanoparticles and evaluation of their drug loading capacity and sustained release potential. J Control Release. 1997;48(2-3): 223-236.

32. Heurtault B, Saulnier P, Pech B, Prust JE, Benoit JP. Physicochemical stability of colloidal lipid particles. Biomaterials. 2003;24(23): 4283-4300.

33. Lechuga-Ballesteros D, Abdul-Fattah A, Stevenson CL, Bennett DB. Properties and stability of a liquid crystal form of Cyclosporine - the first reported naturally occurring peptide that exists as a thermotropic liquid crystal. J Pharm Sci. 2003;92(9):1821-1831.

34. Grasso D, Milardi D, La Rosa C, Impellizzeri G, Pappalardo G. The interaction of a peptide with a scrambled hydrophobic/hydrophilic sequence (Pro-Asp-Ala-Asp-Ala-His-Ala-His-Ala-His-Ala-AlaAla-His-Gly) (PADH) with DPPC model membranes: a DSC study. Thermochim Acta. 2002;390(1-2):73-78.

35. Panicker L. Influence of the leprosy drug, dapsone, on the model membrane dipalmitoyl phosphatidylethanolamine. Thermochim Acta. 2006;447(2):123-130.
International Journal of Nanomedicine

\section{Publish your work in this journal}

The International Journal of Nanomedicine is an international, peerreviewed journal focusing on the application of nanotechnology in diagnostics, therapeutics, and drug delivery systems throughout the biomedical field. This journal is indexed on PubMed Central, MedLine, CAS, SciSearch ${ }^{\circledR}$, Current Contents ${ }^{\circledR} /$ Clinical Medicine,

\section{Dovepress}

Journal Citation Reports/Science Edition, EMBase, Scopus and the Elsevier Bibliographic databases. The manuscript management system is completely online and includes a very quick and fair peer-review system, which is all easy to use. Visit http://www.dovepress.com/ testimonials.php to read real quotes from published authors. 